\title{
Quintessence in Ruling the Nation in the History of Vietnam
}

\author{
Dr Thanh Nguyen Hai ${ }^{1}$, Dr Quang Nguyen $\operatorname{Van}^{2}$ \\ ${ }^{1}$ Ho Chi Minh National Academy of Politics, Hanoi, Vietnam \\ ${ }^{2}$ Ho Chi Minh National Academy of Politics; Academy of Politics Region III, Danang, Vietnam \\ *thanhhaitlh@gmail.com
}

\begin{abstract}
:
Quintessence in ruling the nationis the typical features, becoming the culture and traditions of the nation, converging in the spirit, ideology, and personalities of a leader. The State governance by wisdom in Vietnamese history is associated with the consistency in ideology and people-based actions; putting national interests above personal interests; gracious, tolerant attitudes; promoting the spirit of great national solidarity; taking great importance to study ethics, taking significant advantage towards gifted people and practicing democracy widely. In order to practice the state governance by wisdom, the leaders need to put the national interests and national interests as the ultimate, constantly consolidating and promoting the strength of the great national solidarity, at the same time promoting the roles of the leader as well as well performing the work of cadres.
\end{abstract}

Keywords:Vietnamese history; wisdom; Quintessence in ruling the nation.

\section{Introduction}

According to Vietnamese dictionary, "quintessence is the quintessential and best part" (Institute of Linguistics, 2003, p.995) of a particular subject. The term rule of the country is a saying of Confucius in the book University, rule of the country is actually one of the eight steps to implement the three principles of Confucianism, that is, to rule the country according to discipline and rules. When it comes to the quintessence of national ruling, it means talking about the good qualities, the good side, the positive side, is the most quintessential part of the quintessence of ruling and governing the country, the leader must really become a chimpanzee. Flowers must be a real example of morality, exemplary behavior, an example for everyone to voluntarily follow. The maxim engraved on stele in Tay An from the Qing dynasty as an example of the quintessence of the nation "Quan is not afraid of me being serious but afraid of me being honest; people do not submit to our abilities, but to us with justice; public citizens will not dare to be lazy and incorruptible, the officials will not dare to bully people. Justice will result in wisdom, integrity will bring majesty"(Le Huy Tieu, 2007).

When it comes to the quintessence of the nation, it also means that the value exists within the leading subject itself and in accordance with the objective values, the convergence of many values reaches the peak, is universal and social recognition is relatively stable, which contains both traditional values and inheritance factors that the next generations must acquire, preserve and develop. A person is considered to be the quintessence of the nation, that person must truly represent an exemplary role model, the convergence of typical personality qualities of a person, but also contains the most quintessential values, the best of the nation, containing the pinnacle in Vietnamese traditions for everyone to learn from. Only those who are truly outstanding will be able to win humanity, when the hearts of people have been won, it will create voluntary commitments in others. From thousands of years ago, Pham Trong Yem, the famous god of the Song dynasty in "Nhac Duong Lau Ky", said about the person who reached the quintessence of the nation "worry about the worries of the people, the joy after the joy of the people"(An Hoa, 2020), means to downplay one's ego who is regarded as an elite for society's sake, is honored by society, to be an example for everyone in both history and modernity.

Some people are considered typical in some fields, they may have some outstanding achievements but not necessarily the elite. The individual is considered the quintessence when both crystallizing traditional values, recognized through circumstances and time, recognized by society, because the quintessence of the nation is both historical and a product of history. History created quintessence of the nation and history has chosen them but not anyone else. People with a position in society, not even making any contribution to society, or some people with little 
achievement have hurriedly mistakenly think that it is the quintessence, especially in some young people, that it is a talent, a talent, but not necessarily the elite, the quintessence itself has spread naturally and deeply in society, people voluntarily admit it as Typical values and the need to learn and act without the urge from outside.

The person who is considered as the quintessence of the country in all circumstances always keeps calm, wise to overcome challenges and adversities, it seems that in all difficulties, they keep calm, in action always consistency and consistency. One of the important points that people who are considered the elite of the nation always have a natural attraction to others, maximizing their support for their ideal towards a better society, they act. Not for individuals, but for the common interests of $\mathrm{Xa}$ Tac, the people, always know how to tolerate people's health, these values have the ability to spread widely over many generations and can be transferred. The quintessence of the country here is the crystallization of human qualities and abilities with universal values, creating attraction and attracting people to that value and spreading those values to with the following generations. Therefore, the research on the quintessence of the country is significant both in theory and practice, especially in the current period in Vietnam, with building staff is the decisive factor for success or failure of the method. Cadre work is a "key"stage of the work of building the Party and the political system. Building a contingent of cadres, especially those at strategic level, is the most important task of the Party, and must be done regularly, carefully, scientifically, closely and effectively (The Central Committee of the Communist Party of Vietnam, 2018).

\section{Research design}

Traditional cultural values, role models, and outstanding individuals are always typical examples in society, they can have a profound impact on the development of society despite institutions of different degrees. That is to say that the social regime may be different, but the quintessential values of outstanding people under social regimes, though different, are always accepted and preserved by the following generations and development.

The article uses the approach based on the dependence on the sources of available research to synthesize, analyze and make general assessments of the research problem. The main point of this article is to give assessments and views on the traditional history of Vietnam with unique values that have become quintessential, crystallized among people considered as typical, creating spread to post-learning generations, becoming a value that everyone recognizes as a peak for them to learn and reach (Duong Trung Quoc, 2016). Values are considered the quintessence of crystallization in outstanding individuals, based on the idea that these values will become popular values, continued to be preserved and developed by the following generations. We believe that this framework is very important to understand the fine traditional inheritance of the Vietnamese people gathered in a number of outstanding individuals, becoming an example for the next generations of succession and collect, preserve and transmit. Especially, in the current context, many traditional values and cultural elites are disappearing or assimilated, so the analysis from the available sources contributes to research, understanding and evaluation of pricing and giving directions for maintaining and developing quintessential national values in building human values adapting to the country's renewal context as well as Vietnam's international integration process. South to the world soon gained important achievements.

\section{The quintessence in ruling the nation} of Vietnam

The history of the Vietnamese nation is associated with the foreign struggle against invasions, which has appeared many elite, military geniuses such as Ly Thuong Kiet, Tran Quoc Tuan, Nguyen Trai, and Phan Chau Trinh. , Phan Boi Chau until modern times such as Vo Nguyen Giap, Ho Chi Minh ... they have made great contributions to the development of the national history, the history has gone further back from the names of the elites of this nation. Becoming great, the more people find that there is a convergence of typical moral qualities, national traditions, will and aspirations, a special thing about them being 
able to attract and attract lead to others naturally, become an example for the next generation to follow (Vu Ngoc Khanh, 2001). This is to distinguish from people with certain positions and dignities in society who mistakenly consider themselves as elites, people with leadership positions, managers, even in positions of high authority and important material position does not necessarily become elite.

The quintessence of national rulership always shows the special characteristics of thought and action, becoming the art of ruling that leads others to reach the set goals, the ability to influence, persuade, motivate and create commitments. Moreover, the quintessence of the nation is the quintessence of the people and of the people, their merits and contributions to the country's development are honored by the people (Thai Bao, 2019). One can see outstanding values in the quintessence of the nation:

Firstly, the consistency in thought and action is people-based. Hung Dao Vuong is considered to be the national elite, who early recognized the role of the people in the fight against foreign invaders. In June of the year of Canh Ty 1300, Tran Hung Dao was sick, King Tran Anh Tong visited and asked about the plan to keep the country. It is a national defense policy"(Ngo Si Lien, 1993, p.126). The history of the Vietnamese nation has faced many tough challenges, especially foreign invasions. The court that attaches great importance to the people's strength, promotes the strength of the people, and takes the people as the base will win, because the source of the nation's strength is the people. Ly Thuong Kiet won the Song army thanks to the support of the people, Ngo Quyen defeated the Nam Han army because he relied on the people and the help of local chiefs that Tran kings had gathered. The consensus of the people through the organization of the Dien Hong Conference (1284) mobilized and propagated the entire people to resist the invasion of the world's most powerful Nguyen-Mong empire in the 13th century. King Le Thai To defeated the Minh's invasion with the role of assisting the eminent politician and military man Nguyen Trai, a national hero who once affirmed the power of the people in the article "Customs": Flip the boat to know the people like water (Vu Binh Luc, 2014). In Binh Ngo Dai Dai Nguyen's thought when talking about the role of the people in the prosperity of the country. When boats turn over, they know the strength of people like water, water can carry boats, but water can also flip boats (Quang Minh, 2020).This was soon formed in Nguyen Trai's ideology, in any era, we always have to take the people as the root, the state is born to serve the people, the people who are the ultimate subject of power are still private Outstanding idea so far is always true (Tran Hong Luu, 2020)

Now, under the leadership of the Communist Party of Vietnam, with the consensus of the people, we conquered the invasion of colonialism and mighty empires in the twentieth century. President Ho Chi Minh also pointed out: "Our Party is a revolutionary party, apart from the interests of workers and peasants, our Party has no other interests" (Ho Chi Minh, 2011, Toan Tap, Vol 12, p.587). This proves that no matter what era, the quintessence of the nation rule is always a combination of the will of the ruling government with the support and unanimity of the people. Associated with the destiny of the nation, the people, is the belief, consensus, of the people and the whole society with respect to the leader, each of the leaders' achievements is the convergence, the crystallization of the power of Great block unite the whole nation.

Secondly, put national interests and national interests above personal interests.

National independence and national sovereignty are considered the most sacred. More than anyone, the national elites are always aware of this in order to gather and lead the masses to fight to protect independence, national sovereignty, territorial protection, in such circumstances, even sometimes life, personal feelings and personal interests are sacrificed. Aware of this, outstanding individuals in the national history of the "millennial revenge hero" (Vu Binh Luc, 2014) in the poem Customs are once again reiterated to see that he Heroes never forget their fortunes. For the security of the people, the rule of the country, the flourishing or declining dynasties are all evidenced by their relationship with the people, any dynasty that, for the benefit of the people, can win the hearts of the 
people and mobilize the power of the entire people will win, so the quintessence of the country is the quintessence of the nation. Of course, between personal interests and national interests are always attached and intertwined, but in the face of difficult and challenging circumstances related to the national destiny, the sense and responsibility of the nation will be the religion master, first of all.

Thirdly, gentle, tolerant.

In a letter to the Minh invaders in Dieu Dieu citadel, Dong Quan, Nguyen Trai wrote: "The old people said: The crow went back to his old hometown, the dead fox turned his head back to the mountain. The rest of the animals, how much more are people? ... If you know how to wash your heart, to rebel according to your favor, or stay in order, or to surrender, you will not only wash your shame from before, but also later reviewed. I do not speak and then eat again. If you still regret taking up the position and resisting the king, then when you conquer the city, your crimes will be heavier than the Ngo enemy"(Nguyen Trai, 1969, p.112). Nguyen Trai understood and analyzed very clearly the mentality of the soldier going to the battlefield, not all enemy soldiers had the intent to invade, among them there were people who were forced to, in thought and action. Always with a good disposition, Nguyen Trai used the strategy of "plotting to punish the public mind" (hitting people's hearts), arousing their affection, humanity, and giving up the intention to participate in the war of meaninglessness. Therefore, as soon as the Minh invaders arrived on the shore of our country, Nguyen Trai advocated to both hit and contact, propagate, mobilize and persuade both the Ming soldiers and generals, spreading the harmony of mind the reason for the righteousness made them surrender, avoiding bloodshed for both sides, thus luring the whole expeditionary army of the Ming Dynasty.

The thought of piety and tolerance is not only a policy of Nguyen Trai, but it is crystallized in Vietnamese culture, tradition and transformed into Nguyen Trai's actions, becoming the quintessence of the nation.Up to now, the ideology of the quintessence of the country has been concretized into the basic value of tolerance and peace, becoming the identity of Vietnamese people not only in history but also in its present value. being honored and spread, passed down through generations (Nguyen Thi Tho, Le Cong $\mathrm{Su}, 2020)$ Therefore, a person can be good at leadership, management, around them gather a certain number of people and create some social values, but that does not mean they become the elite of the nation. What people realize the value of harmony must be in the voluntary attraction of others, the ability to gather people into universal values, the thought of the person who is considered to be the quintessence of the nation must blend into national deity, behavior in accordance with national interests, creating attraction and attracting others to follow the values of peace, tolerance without any personal interests or interests. The leader must become a symbol, an example of exemplary status, must truly become the public success of the people.

Fourthly, promote the spirit of great national solidarity.

With more than 54 ethnic groups, the living area of the Vietnamese community spreads over the territory of more than 330,000 square kilometers. But the great thing that the elites that rule the country from the past to now have been doing well is the ability to gather, the ability to promote the spirit of great national solidarity. For these reasons, Clause 1, Article 5 of the 2013 Constitution affirms "The Socialist Republic of Vietnam is a unified nation of all peoples living in the country of Vietnam" (Viet Nam National Assembly, 2013).

In the process of fighting against the invasion of hostile forces, from Ly Thuong Kiet, Hung Dao Vuong, Le Loi, Quang Trung, Vo Nguyen Giap, Ho Chi Minh not only emphasized and practiced the thought of taking the people. As the root cause, it also attaches great importance to promoting the spirit of great national solidarity, demonstrating the high solidarity spirit of the entire Vietnamese nation from generations to now. Moreover, the spirit of solidarity also stems from the objective indispensability, requires the nation and of the times, must unite closely from generation to generation: Many things cover the price of an example water love each other. The spirit of great national solidarity has become a Vietnamese tradition. That tradition has become 
the source of the Vietnamese people's strength.Not only that, tolerance, generosity, altruism combined with solidarity become strength, a basic spirit of a Vietnamese country that can defeat all invading enemies, any difficulty is possible to be surpassed (Nguyen Hoai Van, 2016)

Today, with the strong development of information technology, our social networks have more and more conditions to popularize and develop these achievements in building the spirit of national solidarity, propagating views and ways of the Vietnam Communist Party, making each masses and party members imbued with the Party's ideology, the spirit of great unity to lead the people to successfully implement all Party Resolutions, becoming a symbol of the striving.

Fifthly, attach importance to study ethics, respect for talented people.

Vietnam electoral regime was formed very early, starting in 1075 Ly Nhan Tong dynasty and ending in 1919, Khai Dinh dynasty, along the length of 844 years, Vietnamese feudal dynasties organized all. In 183 exams, 2,898 people got the doctorate, of which 56 people passed the poinsettia, even some people passed the status quo at the age of only 13 , the oldest one was over 80 years old (Hoang Minh, 2019). The feudal exam regulations were very strict, candidates could be necked, beaten, and imprisoned if they violated the rules. Under the Nguyen Dynasty, the scholar who brought documents into the examination room would be strangled, punished with 100 whips, the test was strictly regulated on the way of expression and presentation (Nguyen Thanh Diep, 2018) ... The exam does not discourage test takers, it is important that they always have a desire to contribute to the development of the country.

Up to now, the spirit has continued to be strong, international Olimpic exams that the Vietnamese delegation participates in have contestants winning high prizes, international skill contests always have prizes. In the country, we are also constantly looking for talents through many competitions, especially the annual contest for selecting excellent students to affirm that we always attach great importance to study ethics, to find talented people, who are talented and virtuous. King Le Thanh Tong stated 5 criteria to choose Ly Truong, which also fully covers the two criteria of morality and ability, namely: "learning force gives birth to students, warm family, Physical strength, Moderate virtue, Language of credibility". The great poet Nguyen Du also taught: "The word heart is equal to three talented words". Reformer Li Kuan Yew generalized: "Having virtue without talent is easy to delay. Having talent without virtue is easy to chaos (Le Doan Hop, 2018). Regardless of the era, the person who is considered the elite must have both virtue and talent. Having ethics will be exemplary, not exemplary as being unethical, success without arrogance, failure not to be discouraged is the true way of ruling elites. A person with virtue must meet 3 qualities: exemplarity, democratic practice, cultural behavior.

Appreciation of talents has become the tradition and ideology of Vietnamese people, and talented people are considered the original national spirit, a distinctive feature in Vietnam's ruling art, the art of ruling the country, ancient people once said" used, users must believe, not use". Talents have been affirmed by history over time, erected statues, registered on stele, named streets, street names, their names are in history, people recognize the merits, each of them. Some of them become the cultural elite, some become the quintessence of the nation, creating values of the culture that today's generations are inheriting, supplementing and developing.

Sixthly, practice democracy widely.

The feudal dynasties, especially the Ly, Tran and Le dynasties, stepped up the implementation of democracy in order to find talented people and gather people. Binh Than Conference (convened by King Tran Nhan Tong in October 1282), Dien Hong Conference (held in 1284 at Thang Long capital city, led by Supreme Emperor Tran Thanh Tong to convene elders throughout the country to return to the front porch. Dien Hong's referendum, to ask about the policy of a draw or fight when the Nguyen Mong army invaded Vietnam for the second time). During the Nguyen Dynasty, under King Minh Mang set up a community institution to discuss and propose to the king issues related to the country, villages (Duong Trung Quoc, 2015). 
Today, the practice of democracy is a leading principle which has been established in the 2013 Constitution, in Clause 2, Article 3 "The Socialist Republic of Vietnam is owned by the People; All state power belongs to the People ", in Article 3 clearly states" The State guarantees and promotes the people's mastery "(Viet Nam National Assembly, 2013). Practicing the principle of democracy to limit authoritarianism, authoritarianism, and promote the people's wisdom is also a Party's tradition and art of leadership in national construction and development.Democracy has become a human value, a traditional symbol of Vietnam, more meaningful in the context of globalization, because democracy is the morality of the leaders, democracy is the best way to gathering the masses of people, it is the best way for leaders not to make mistakes, to build a spirit of broad solidarity, not only domestically but with international friends (Tran Nguyen Viet, 2002)

\section{Some issues that need attention in} terms of building and developing quintessence of state rule in Vietnam

Inheriting the quintessence of the nation's dominance in the history of the Vietnamese nation, in leadership, management, all levels of committees and authorities need to pay attention to the following key issues:

The first, always put national interests, national interests as the ultimate.

The leader must always put the interests of the nation and the people above their personal interests, must be a truly typical example, must become a solid support for the people and subordinates. In policy formulation, policy making needs to take the people as the object to serve. In the article "How to win the hearts of the people", published in the National Salvation Newspaper, No. 65, on October 12, 1945 , President Ho Chi Minh emphasized: "To give the people love, to gain the hearts of the people, what is beneficial people have to do their best, whatever is harmful to the people must be avoided"(Ho Chi Minh, 2011, Toan Tap, Volume 4, p.51). Therefore, right from the planning stage, selecting staff requires a strategy, avoiding haste, choosing the wrong person, the more difficult it is to choose staff, the more convenient it is to employ people to work together. The Party also pointed out the difficulties in cadres work, the biggest difficulty in the assessment and evaluation, the more appropriate the evaluation and the better the selection of excellent cadres to foster, educate and train to lead Revolutionary career.

The second, consolidate and promote the strength of the great block of solidarity throughout the nation.

National solidarity is not only a Vietnamese tradition but also an elite value of the Vietnamese people, the quintessence of the National Assembly converging in the leaders. In the process of leading the revolution, our Party has always identified great national solidarity as a strategic line, which is the driving force and great strength. President Ho Chi Minh summarized "Our people have a passionate patriotism. It's one of our precious traditions. From the past up to now, every time the Fatherland was invaded, that spirit was excited, it combined into an extremely strong and big wave, it passed through all dangers and difficulties, it engulfed everything. both floods sell water and floods rob the country" (Ho Chi Minh, 2011, Toan Tap, Volume 7, p.38). The ruling party becomes the quintessence when gathering and mobilizing the people to promote the spirit of patriotism, which is also a factor in the strength of Vietnam from tradition to modernity.

In the process of building, defending and developing the country, and integrating with the world more and more deeply, we must further strengthen the block of great national unity, promote the tradition of patriotism and humanity meaning, tolerance. To realize this, each leader needs a deep sense of the formulation and issuance of guidelines, resolutions and policies that must come from objective reality, from the lives of the people, for national interests, constantly care for and protect the people's legitimate and legitimate rights and interests. The history of the Vietnamese people from past to present is the history of the struggles to build and defend on the Country, all victories are associated with the role of the masses, demonstrating the spirit of great national solidarity. So, every era must arouse and create confidence for the people, 
constantly expanding and building people's hearts (Nguyen Van Thang, 2020).

Today, before the strong onslaught of hostile forces in all aspects, especially with the support of the media, moral corruption in a part of the party members, the leaders more and more steadfast, always vigilant to fight corruption, to maintain the revolutionary stance. Moreover, promoting the national solidarity tradition also has the gathering and solidarity with the progressive people in the world, expanding international relations to take advantage of all international support and assistance, in order to build to firmly erect and defend the Fatherland, fight to defeat all schemes of reactionary and hostile forces.

The third, practice and strongly promote the role of the leader.

The term leadership is often used every day, but its meaning and content are not noticed and grasped by everyone, there is confusion, or there is a similarity with this term, even the opinion that leadership is a function of management (Phan Huy Duong, 2014, p.23). The theoretical researchers of "leadership learning" so far have not given a unified definition of leadership. However, it can be seen that the leading subject can be associated with abstract aspects of life, leadership in the political field, leaders are politicians. The leader is people. The goal of a leader is to guide, point, and foresight, towards strategic issues, long-term goals, and set guidelines and directions. Leaders use measures of encouragement, persuasion, and influence based on morality, affecting people's consciousness. Leadership belongs to the category of ideological, theoretical and ethical, not coercive. Leadership tools are prestige, soft power and the result is innovation and qualitative changes in the development of the organization. The function of leadership is to create visions, motivate and motivate individuals' development. In order to distinguish this from authoritarian rule, authoritarian rule, the elite rule of the country must stand on the stance and point of view of leadership science.

Therefore, the leader must be able to gather, motivate others to work, see the meaning of the job and work with sincere and passionate attitude. The leader must use the spirit of service to work, inspire others and overcome the authoritarian situation, lack of democracy, always consistent with the viewpoint "people are the roots", "democracy is democracy". In the leadership, ensure that all state powers belong to the people, gather the people's strength in the cause of building and defending the country. The fact of Vietnam's history has proven that the flourishing times of the nation all played a great role in setting the example and correct decisions of the kings and leaders of the country, the nobility of the law, affirming virtues in the leadership of their country through practice, on the contrary, the decline of the nation is sometimes caused by kings who are less than intelligent, not capable of manipulating the country (Nguyen Thi Quyet, 2020). Leaders must be really exemplary, always listen to the opinions of the people, be close to the people, understand the people, and learn from them. Overcoming the thought of selfishness, "thinking in term", corruption, when there is no position or low position, they will speak strongly, but when they have a position, they will be bureaucratic, corrupt, away from the masses.

The fourth, well perform cadres work.

Staff work has many stages, many steps, this is an extremely difficult job, but it does not mean that it cannot be done well. When recruiting, it is necessary to be fair and objective, for the job to choose people, it is necessary to discover and select cadres who "have an innovative mindset, have the ability to formulate paths, policies, leadership and direction, implementation organization"(The Central Committee of the Communist Party of Vietnam, 2018). In the cadre assessment, our Party also admitted so far, "cadre assessment is still a weak stage, not reflecting the true nature" (The Central Committee of the Communist Party of Vietnam, 2018), but that does not mean we cannot have The right assessment method, but the assessment should be based on standards of ethics and talent, leaders must be exemplary, overcome the state of respect, permissiveness or prejudice. From the eighteenth century, the first German Prime Minister, Otto von Bismarck (1815-1898) once said: Completing the process or the law often takes time, so it is important to have good officials, the law is not 
perfect and official with conscience is better than having a perfect law without a conscientious official (Tran Van Tho, 2020).

In fact, there are cadres who, before being appointed to higher positions, have worked hard, building a spirit of solidarity, sticking with colleagues, building close relationships with the people and colleagues. thus, gaining the trust of the organization, the people, and the Party, but when being appointed to a higher leadership position, it failed to maintain its stance, fell into a decline of personality to the point of enforcing self-discipline and the law. The biggest reason is that the individual is not brave enough to overcome the harsh challenges of the leadership context, the more leadership challenges increase, the more leaders must be aware of political bravery, expectation of the people, the Party's credibility, to really become the ruling elite.

\section{Conclusions}

The quintessence of the country is not only historical but also modern value of Vietnam, showing the stability in character, the convergence of typical values, before the events that do not turn around and communicative in the leader. The quintessence of the country must be for the people, for the general development and progress of the society, as a symbol of the striving of generations to come, it must be pervasive for people to have a need towards, want to act on it. The application and promotion of Vietnam's national elites and elites becomes the traditional heritage in leadership activities of leaders, party committees and authorities at all levels. Especially in the context that Vietnam is integrating with the world more and more deeply, the inheritance and promotion of the quintessence of the country have become more and more important issues, to gather the masses of people, as well as the formula to practice democratic leadership principles. On the other hand, in the current context, it is necessary to find and foster the quintessence so that they can truly become the quintessence of the country, overcoming the new situation that only a few contributions in some areas were considered the quintessence soon and they may be talented, but not elite. The realization of this has important implications for good staff performance, especially those who are really typical people to be appreciated, use their talents, and strengthen and strengthen the trust of staff of ministries, party members and people towards the The Central Committee of the Communist Party of Vietnam and State of Vietnam.

\section{References}

1. An Hoa. (2020, April, 2). Motto of the old intellectuals: Worried about the worries of the world, Retrieved November 6, 2020, from https://trithucvn.org/van-hoa/phuong-chamsong-cua-tri-thuc-xua-lo-truoc-cai-lo-cuathien-ha.html.

2. Duong Trung Quoc (2016): Vietnamese quintessence must be attributed to humans, Retrieved November 6, 2020, from http://giad Vacations.vn/xa-hoi/nha-su-school-schoolquoc-quoc-quintessential-viet-new-to-people0160129162931696.htm.

3. Ha Thanh. (2017). The art of "justice" in military thought by Nguyen Trai, The AllPeople National Defense Magazine, Retrieved November 6, 2020, from http://tapchiqptd.vn/en/tim-hieu-truyenthong-quan-su /nghe-thuat-tam-cong-trongtu-tuong-quan-su-cua-nguyentrai/10633.html.

4. Ho Chi Minh. (2011). Toan Tap, Volume 4, National Political Publishing House, Hanoi.

5. Ho Chi Minh. (2011). Toan Tap, Volume 7, National Political Publishing House, Hanoi.

6. Ho Chi Minh. (2011). Toan Tap, Volume 12, National Political Publishing House, Hanoi.

7. Hoang Minh. (2019, November, 27). Symbols of Vietnam's electoral education, Retrieved November 7, 2020, from http://daidoanket.vn/bieu-tuong-cua-nen-giaoduc-khoa-cu-viet-nam-453310.html.

8. Le Doan Hop. (2018, September, 19). Taking a look at the staff standards of industrial age 4.0, Retrieved November 6, 2020, from https://www.moha.gov.vn/baucu/tin-tuc-sukien/tieu-chuan-can-bo-duc -a-new-businessindustry-4-0-38667.html.

9. Le Huy Tieu. (2007). Prime Minister Chu Dung Co's life after his retirement, Retrieved November 6, 2020, from http://cand.com.vn/Quoc-te/Cuoc-song-cua- 
Thu-tuong-Chu-Dung-Co- after-day-to-huu118327.

10. Nguyen Hoai Van. (2016). Tolerance, tolerance, altruism - The basic spirit of a people's politics. Journal of Political Theory, (7), pp.83-89.

11. Ngo Si Lien. (1993). The Complete History of Dai Viet, Social Science Publishing House, Hanoi.

12. Nguyen Tai Thu. (2001). Ability to develop Vietnamese traditional values in the face of globalization. Philosophical Journal, No. 5 (123), p.25-32.

13. Nguyen Thanh Diep. (2018, July, 28). Neck a month, beat 100 whips if bringing materials into the examination room, Retrieved November 9, 2020, from https://vietnamnet.vn/vn/giao-duc/tuyensinh/gong-co-mot-thang-danh-100-roi-neumang-tai-lieu-vao-phong -thi-466755.html.

14. Nguyen Thi Quyet. (2020). Some basic characteristics of Vietnamese patriotism in the Ly - Tran dynasty. Journal of Philosophy, No. 7 (350), p.66-74.

15. Nguyen Thi Tho, Le Cong Su. (2020). Nguyen Trai's concept of tolerance and solidarity and its present value. Philosophical Journal, no.7 (350), p.57-65.

16. Nguyen Trai. (1969). Toan tap. Social Science Publishing House, Hanoi.

17. Nguyen Van Thang. (2020). The concept of the people believing in the history and its significance for building the popular posture in our country today. Journal of Philosophy, No. 9 (352), p.41-48.

18. Phan Huy Duong. (2014). Leaders of the public sector, National University Publishing House, Hanoi, Hanoi, p.23.

19. Quang Minh. (2020, November, 6). Carrying a boat is a people, flipping a boat is also a people Military Region 2, Retrieved November 6, 2020, from http://quankhu2.vn/cho-thuyen-la-dan-latthuyen-cung-la-dan/.

20. Viet Nam National Assembly, (2013). Constitution of the Socialist Republic of Vietnam, November 28, 2013.

21. Thai Bao. (2019, December, 26). Inheriting the quintessence of the country in building and defending the Fatherland, Propaganda Magazine, Retrieved November 6, 2020, from http://tuyengiao.vn/van-hoa-xa-hoi/ke-thuatinh-hoa-tri-quoc-trong-xay-dung-va-bao-veto-quoc -126070 .

22. The Central Committee of the Communist Party of Vietnam. (2018). Resolution No. 26NQ / TW dated May 19, 2018 focused on building a contingent of cadres at all levels, especially at strategic level, with sufficient qualities, capabilities and prestige, on a mission level. Hanoi.

23. Tran Hong Luu. (2020). Thought about Nguyen Trai's time. Philosophical Journal, No. 3 (346), pp.45-52.

24. Tran Nguyen Viet. (2002). Traditional humanistic values of Vietnam in the context of globalization. In Nguyen Trong Chuan "Traditional values facing the challenges of globalization", National Political Publishing House, Hanoi.

25. Tran Van Tho.(2020, August, 14). Leader's Self-respect. Retrieved November 6, 2020, fromhttps://nld.com.vn/trich-dan-nong/tutrong-cua-quan-chuc20200814094108143.htm.

26. Institute of Linguistics,(2003).Vietnamese Dictionary, Da Nang Publishing House, Da Nang.

27. Vu Binh Luc. (2014, July, 24). Lost people's hearts, then what? (About Nguyen Trai's poem Quan Hai), Retrieved November 6, 2020, from https://vanhien.vn/news/Matlong-dan-thi-con-gi-Ve-bai-tho-Quan-haicrab-Nguyen-Trai-38405.

28. 28. Vu Ngoc Khanh. (2001). Looking for the "religion" of the nation. Philosophical Journal, No. 5 (123), pp.51-53. 